\title{
Keynes: \\ o liberalismo econômico como mito ${ }^{1}$
}

\author{
Pedro Cezar Dutra Fonseca ${ }^{2}$
}

\begin{abstract}
Resumo
$\mathrm{O}$ artigo tem por objetivo recuperar os principais argumentos de Keynes em suas críticas ao liberalismo econômico, este entendido como as teorias e práticas de política econômica adotadas pelo mainstream no campo da Ciência Econômica e simbolicamente respaldado na máxima do laissez-faire. Embora as obras de maior fôlego de Keynes situem-se no campo da economia teórica, há trabalhos seus que permitem detectar sua ideologia e, mais explicitamente, o teor de sua crítica ao liberalismo clássico. O ensaio mostra que, em um mundo polarizado entre o nazi-fascismo e a experiência stalinista soviética, Keynes articula uma visão muito particular em rejeição a ambos e em defesa da democracia representativa e da livre iniciativa. Todavia, com possível respaldo no pragmatismo filosófico, o liberalismo econômico é entendido como uma construção mítica e incompatível com o capitalismo do século XX.
\end{abstract}

Palavras-chave: Keynes; Liberalismo; História do pensamento econômico; Ideologia keynesiana; Antiliberalismo.

\section{Abstract \\ Keynes: the economic liberalism as a myth}

This paper aims at highlighting Keynes' main arguments in his criticism of economic liberalism, conceived of as the theories and the praxis of economic policy adopted by the mainstream thinkers in the field of economics and symbolically based on the laissez-faire approach. Although Keynes' ultimate works are in the field of economic theory, a number of them show his political line of thought, more evidently his criticism of classical liberalism. The paper demonstrates that, in a world polarized between nazi-fascism and the Soviet Stalinist experience, Keynes articulates a very peculiar view against both, in favor of a representative democracy and a free market economy. However, possibly based on philosophical pragmatism, economic liberalism is seen as a myth that is not compatible with $20^{\text {th }}$ century capitalism.

Key words: Keynes; Liberalism; History of economic thought; Keynesian ideology; Anti-liberalism. JEL B20, B22, B31.

\section{Um crítico singular}

Dentre os críticos do liberalismo, John Maynard Keynes (1883-1946) sem dúvida ocupa lugar singular. Suas ideias sobre o tema fogem a qualquer padrão

(1) Trabalho recebido em novembro de 2009 e aprovado em maio de 2010.

(2) Professor Titular do Departamento de Ciências Econômicas da Universidade Federal do Rio Grande do Sul (UFRGS)/Pesquisador do CNPq (Conselho Nacional de Desenvolvimento Científico e Tecnológico), Porto Alegre, RS, Brasil. Agradeço a Fernando Ferrari Filho e Maria de Lourdes Mollo pelas valiosas sugestões, evidentemente eximindos-os das deficiências remanescentes, e ao bolsista de Iniciação Científica Jorge Varaschin. E-mail: pedro.fonseca@ufrgs.br.

Economia e Sociedade, Campinas, v. 19, n. 3 (40), p. 425-447, dez. 2010. 
com relação aos que lhe antecederam. Keynes não era socialista, criticava as experiências como a da Rússia soviética e suas referências a Marx quase sempre foram em tom crítico. Por outro lado, desprezava o nazi-fascismo e o corporativismo, responsáveis por empolgar boa parte de seus contemporâneos, também com uma retórica antiliberal e com forte apelo estatista. Outras vertentes críticas ao liberalismo, ainda de cunho mais conservador, como as correntes cristãs inspiradas na Rerum Novarum ou no positivismo político de Comte, nem de longe é possível detectar influência em suas obras. As matrizes intelectuais que ele próprio reconhece, como Malthus ou mesmo Marshall, restringem-se ao campo da teoria econômica stricto sensu. Mesmo assim, alguns escritos de sua autoria permitem descortinar sua ideologia, embora muitas vezes neles evite o caráter axiológico explícito. Resta ao analista a difícil tarefa de decifrá-la, e esse talvez se arrole como mais um motivo a justificar a polêmica resultante da existência de diversas leituras sobre sua obra. Todavia, como se mostrará adiante, há bastante coerência ao longo da produção intelectual de Keynes com relação à temática aqui abordada.

A Weltanschauung liberal, desde seu nascedouro, comoveu tanto defensores apaixonados como ferozes contendores. Este ensaio tem como objeto central elucidar os argumentos de Keynes em suas críticas ao liberalismo econômico, este entendido como as teorias e práticas de política econômica adotadas pelo mainstream no campo da Ciência Econômica e simbolicamente respaldado na máxima do laissez-faire. $\mathrm{O}$ texto se encontra estruturado em mais quatro seções, além desta introdução. A segunda e seguinte enfoca o que talvez seja a marca mais definidora do antiliberalismo de Keynes: o fato de não significar uma rejeição ao capitalismo. Mais além: em várias passagens de sua obra, ressalta o papel do investidor, a importância da propriedade privada e da livre iniciativa como essenciais para uma sociedade mais justa e eficiente. Todavia, seu argumento é complexo, pois critica o especulador e, reiteradamente, propõe aquilo que os empresários mais repelem: controle do Estado em seus negócios, regulamentação e limites. Ao contrário da teoria econômica tradicional, cujos modelos associam capitalismo e liberalismo de modo que ambos passam a ser entendidos como fenômenos indissociáveis, em Keynes há um nítido entendimento do contrário: o primeiro, com suas instituições, é tratado como um sistema econômico, enquanto o segundo como um conjunto de ideias que servira o propósito de influenciar e justificar atos de governos e policymakers desde o final do século XVIII. Keynes reiteradas vezes ponderou que estas ideias e teorias foram atropeladas pelos acontecimentos do século $\mathrm{XX}$, de modo que se fazia mister substituí-las por uma nova forma de pensar a economia e, portanto, de praticá-la. A terceira seção aborda sinteticamente as novas concepções introduzidas por Keynes na teoria e na formulação da política econômica, sempre com a pretensão de resgatar sua crítica às teses assentadas no liberalismo e que se 
tornaram o mainstream acadêmico britânico (e internacional) no século XIX. Assim, o esforço de síntese a ser elaborado não pretende ser um resumo ou, tampouco, o arrolamento dos pontos principais do que se denominou "revolução keynesiana" - tarefa a qual já se dedicaram centenas de seus admiradores e opositores -, mas tão somente destacar aqueles aspectos mais relevantes para elucidar o alcance e o significado de seu antiliberalismo. A quarta seção volta-se ao Keynes político e procura desvendar sua ideologia mais imediata, na práxis cotidiana, contra os adversários não só da ortodoxia conservadora, mas também os comunistas e nazi-fascistas. Finalmente, a quinta e última parte, a guisa de conclusão, apresenta alguns pontos recorrentes no pensamento de Keynes sobre o tema e brevemente recorda sua influência posterior e seu legado.

\section{Liberalismo: uma ideologia divorciada da realidade}

Uma característica marcante da crítica de Keynes ao liberalismo é seu apelo à razão prática. O liberalismo está errado porque "não funciona". Poderia até ter sido útil no passado; no mundo do século XX, e principalmente com a perda da hegemonia britânica, deixara de sê-lo. Sua existência é questionada tendo como critério a utilidade. Neste aspecto, lembra o pragmatismo de William James, pelo menos quando este defende como parâmetro para identificar uma verdade o seu valor para a vida concreta, do qual resulta, portanto, que não é algo definitivo e imutável: "o pragmatismo pega a noção geral de verdade como alguma coisa essencialmente ligada à maneira pela qual um momento em nossa experiência pode levar-nos a outros momentos aos quais valerá a pena ser levado" (James, 1979, p. 73). Assim, verdades que haviam encantado gerações de economistas e conquistado políticos, empresários e tornado-se senso comum ao conquistar os não especialistas - "oferta de moeda causa inflação", "o mercado tende ao autoequilíbrio", "o Estado deve restringir-se à segurança e justiça", "a poupança favorece o crescimento econômico", "o juro é a remuneração pelo sacrifício da abstinência" - são postas em questão pela experiência. Keynes rejeita, portanto, argumentos dedutivos, apriorísticos ou explicitamente valorativos ao arquitetar sua construção teórica, cujo desaguadouro consiste na rejeição aos princípios liberais.

No contexto em que vivia, a primeira metade do século $\mathrm{XX}$, predominavam na elite intelectual e econômica inglesa as ideias liberais, apesar das guerras e mesmo após a crise de 1929. Fora sob a égide desse ideário que o Império Britânico atingira seu apogeu; o liberalismo justificara e legitimara a busca do lucro, o padrão-ouro, a abertura dos mercados e as conquistas coloniais "civilizatórias". "Para que intervenção do Estado, se nunca precisamos disso?" era a pergunta mais difundida e a mais difícil de responder aos interlocutores 
predispostos a reagir em sentido contrário. ${ }^{3}$ E estes não existiam apenas na GrãBretanha, posto que a influência das teses liberais, a despeito de enfrentar opositores desde seu nascedouro, dominava os círculos europeus e, praticamente, os segmentos mais esclarecidos e de elite no mundo inteiro. Para estes, o capitalismo não estava em questão, mas havia certa ansiedade em saber por que o mundo mudara e o conhecimento econômico estava em crise. Coube a Keynes, discípulo de Marshall e formado na ortodoxia de Cambridge, ser o porta-voz da nova época, desapegar-se do passado e apontar para o novo. Sua construção teórica foi fortemente condicionada por este contexto conservador, saudoso dos tempos áureos do Império Britânico - e, por isso, para alguns ela pareça "moderada", muitas vezes "conivente" com o capitalismo e com base em argumentos excessivamente pragmáticos. Talvez com essa retórica perdesse em ênfase, mas ganhava em adesão e convencimento. De fato, seu pensamento difundir-se-á mais do que qualquer outro após a Segunda Guerra. A partir dessa, iniciou-se um período de forte crescimento sustentado, com interveniência estatal e relativa distribuição de renda: a "era keynesiana" ou "de ouro" consagrou a influência de seu pensamento, contrariando seus críticos cujo esforço consistia em restringi-lo a um teórico da crise ou intérprete da Grande Depressão.

Os trabalhos mais conhecidos de Keynes e nos quais esclarece seus valores e sua visão de longo prazo são: (a) "O fim do 'laissez-faire”, de 1926; (b) "As possibilidades econômicas de nossos netos", apresentado inicialmente em 1928, mas publicado apenas em 1930. Ambos constam do volume IX de seus Essays in persuasion (1972). ${ }^{4}$ E também (c) o capítulo 24 da Teoria geral do emprego, do juro e do dinheiro, de 1936, intitulado "Notas finais sobre a filosofia social a que poderia levar a Teoria Geral”.

No primeiro - talvez o mais importante para os propósitos deste artigo -, Keynes resgata as origens do liberalismo e, com extremo poder de síntese, elenca seus principais fundamentos filosóficos e aponta suas críticas. Seu ponto de partida é indagar por que as ideias do laissez-faire e do individualismo conquistaram tantos adeptos: "Ainda hoje, não deixamos de dançar a mesma música. Mas paira no ar uma transformação" (Keynes, 1978) (note-se que o escrevera antes da Grande Depressão, como fruto de uma conferência que dera em Oxford em novembro de 1924). Em poucos parágrafos, repassa, dentre outros, Locke, Hume, Paley, Bentham, Rousseau, Darwin, Burke, Godwin, Malthus, Cobett, Colbert, Smith, Marshall e o Marquês d'Argenson, a quem é atribuída a

(3) Apesar do predomínio das ideias liberais, a intervenção estatal não esteve ausente dos principais estados nacionais europeus (e também do Continente Americano) no século XIX. Todavia, como Mostra Polanyi (2000), a Pax Britanica e a hegemonia do pensamento teórico do que Keynes chamou de "Economia Clássica" associaram-se fortemente ao longo daquele século.

(4) Publicados em português em 1978; ver "Referências Bibliográficas". Deste foram extraídas as citações a seguir mencionadas no texto. 
declaração, pela primeira vez, da famosa frase "Para governar melhor é preciso governar menos" ("Pour gouverner mieux, il faudrait gouverner moins").

A gênese do individualismo remete à polêmica que envolveu os intelectuais de língua inglesa entre o final do século XVII e meados do século XVIII sobre como seria possível a sociabilidade em uma sociedade assentada na busca incessante do lucro e no individualismo, em que os valores medievais (moderação, temperança, caridade) cediam espaço a outros, os quais enalteciam justamente o contrário (acumulação, egoísmo, iniciativa individual). Sem uma autoridade central, representada pela Igreja ou pelo rei com direito divino, como apenas a impessoalidade do mercado definiria as regras mais básicas de convivência, até então ditadas pela política ou pela religião, refletidas, no campo econômico, em questões como o que produzir, de que forma, como repartir o produto e por que meios? Até Adam Smith, buscava-se a resposta no âmbito da metafísica: qual era a essência do homem, como ele seria no estado de natureza? $\mathrm{Na}$ tentativa de sumariar um complexo de ideias em poucas palavras, mesmo correndo o risco da ultrassimplificalção: para Locke (assim como para Rousseau, no contexto francês, cuja arquitetura teórica acabará por afastar-se do liberalismo e preceder o socialismo dito "utópico" de St. Simon e Fourier), o homem era naturalmente virtuoso e altruísta; com a evolução social, sua liberdade natural deveria ser substituída por um contrato social, de modo que a instituição Estado resultaria de uma adesão como forma de garantir a vida, a liberdade e a propriedade (tríade cuja ordem mais de uma vez Locke inverteu ao arrolar). Já para Hobbes, no estado de natureza prevaleciam os instintos humanos de violência e ganho; o Estado surgira como uma máquina para adestrá-lo e tornar possível a vida em sociedade, a qual, deixada sem freios, tenderia à desagregação. A polaridade entre estado liberal e absolutista, ou entre mercado e intervencionismo, desaguava na pergunta sobre o que preponderaria no homem no estado de natureza: o altruísmo ou o egoísmo, a solidariedade ou o individualismo, a bondade ou os instintos destruidores?

Segundo Napoleoni (1978, p. 40-47), autor de um resumo clássico desta controvérsia, coube a Hutcheson, mestre de Smith em Glasgow, sintetizar essa dualidade psicológica e preparar o campo para o trabalho deste último em Teoria dos Sentimentos Morais. Nessa obra, a busca de solução viria com a noção de simpatia: os vícios privados tornam-se virtudes públicas (a lembrar a fábula das abelhas de Mandeville). Destarte, Smith começa uma reflexão cuja expressão mais acabada encontra-se em A Riqueza das Nações, onde desloca a solução do conflito do âmbito da Filosofia para a Economia Política; nela, a polaridade é falsa, pois não há contradição: o egoísmo privado transforma-se em virtude social. Este aforismo resiste como o principal fundamento do liberalismo econômico, daquela época aos dias atuais. A sociedade regida pela impessoalidade do mercado e pelo 
autointeresse não apenas não se desagregará, mas trará o melhor para todos. Se cada um for livre para buscar seu máximo ganho e prazer (aí já com certo hedonismo que nada tem ver com a ética puritana), o resultado será melhor para o conjunto da sociedade. Na versão de economia de bem-estar neoclássica, este princípio encorpa-se com linguagem matemática e, a partir de certos supostos, "demonstra-se" (entre aspas porque a partir de pressupostos e axiomas, pelo método da dedução, sem qualquer recurso à fundamentação empírica - método que desconfortava Keynes) que do somatório das maximizações de funções individuais resulta o ótimo social. Não precisa haver coerção estatal para obrigar o padeiro a acordar bem cedo, recorrendo-se ao exemplo clássico de Smith: a sociedade desfruta o pão novo porquanto o padeiro apenas quer ganhar dinheiro. Esta construção de Hutchson/Smith é engenhosa, dentre outros motivos, porque não deixa de recorrer à raiz filosófica: nela ainda perdura o entendimento ahistórico de um homem egoísta no estado de natureza. Todavia, não a explicita; dissimula-a com apelos à "razão prática" e fixa-se em suas consequências para advogar a falsidade da questão. O viés pragmático revela-se como a filosofia da "não-filosofia", que não questiona as causas, mas avalia resultados - e aí a diferença com relação a Rousseau: Keynes cita Stephen para afirmar que, diferentemente de Locke, para o francês "a igualdade não é apenas ponto de partida, mas o objetivo" (Keynes, 1978).

A repulsa de Keynes a Hutchson/Smith e seus seguidores mais influentes, como Ricardo e Say, é enfática e levou-lhe a redigir uma de suas passagens mais citadas, não só por seu conteúdo, mas por seu estilo e inspiração:

Esclareçamos desde o início os princípios metafísicos ou gerais sobre os quais, de tempos em tempos, se fundamentou o laissez-faire. Não é verdade que os indivíduos possuem uma "liberdade natural" prescritiva em suas atividades econômicas. Não existe um contrato que confira direitos perpétuos aos que têm ou aos que adquirem. $\mathrm{O}$ mundo não é governado do alto de forma que o interesse particular e o social sempre coincidam. Não é administrado aqui embaixo para que na prática eles coincidam. Não constitui uma dedução correta dos princípios da Economia que o autointeresse esclarecido sempre atua a favor do interesse público. Nem é verdade que o autointeresse seja geralmente esclarecido; mais frequentemente, os indivíduos que agem separadamente na promoção de seus próprios objetivos são excessivamente ignorantes ou fracos até para atingi-los. A experiência não mostra que os indivíduos, quando integram um grupo social, são sempre menos esclarecidos do que quando agem separadamente (Keynes, 1978, p. 120).

Nota-se claramente que os argumentos de Keynes tornam-se convincentes ao tocar na moleira dos fundamentos teóricos de seus adversários (e, por certo, tendo em vista o público a que se dirigia): o liberalismo está errado não por uma razão moral, mas porque fere a realidade e o senso prático. Quer dizer, é tão medieval como os princípios feudais contra os quais os liberais haviam se rebelado 
no passado: que diferença há entre a "mão invisível" smithiana, ou mesmo entre o leiloeiro clarividente de Walras, com a divindade religiosa ou força exógena política (como o rei absolutista), últimos recursos para garantir uma ética que compatibilizasse atos individuais e sociais? A crença em um mercado "que não erra" não passa de uma metafísica como todas as outras. Por isso, liberdade natural não existe, contrato perpétuo é ficção, não há força externa ou "do alto" (nem "mão invisível" nem força divina) que garanta a coincidência entre somatório dos ótimos individuais e ótimo social. Os indivíduos não possuem a racionalidade livresca e pré-suposta sem provas, nenhuma força agrega a sociedade per si. O início da última sentença revela o âmago de sua construção retórica, com grifos seus: "a experiência não mostra..." (Keynes, 1978). Em outras palavras: o individualismo liberal funda-se num mito. Na terra de Hume e Locke, cujo empirismo exigia que a ciência deveria submeter-se ao "altar dos fatos", existiria argumento mais eficaz para criticar o liberalismo? ${ }^{5}$ Keynes, ao final, enfatiza que sua crítica não se estende ao capitalismo como sistema econômico: "o capitalismo provavelmente pode se tornar mais eficiente para atingir objetivos econômicos do que qualquer sistema econômico conhecido, mas (...), em si, ele é de muitas maneiras sujeito a inúmeras objeções” (Keynes, 1978, p. 126).

Já o segundo paper mencionado, "As possibilidades econômicas de nossos netos" (Economic possibilities for our grandchildren), é um texto otimista e a crítica ao liberalismo é mais sutil. Keynes reivindica uma atitude politicamente "de centro" e advoga para si uma postura de equilíbrio ao condenar aqueles que "tumultuam o mundo": os "revolucionários", adeptos de transformações violentas, "para quem as coisas vão tão mal que nada nos pode salvar", e os "reacionários", para os quais "o equilíbrio da vida econômica e social é tão precário, que não devemos nos arriscar em fazer experiências" (Keynes, 1978, p. 151). Vislumbra para dentro de um século um mundo melhor, na confiança de que "a humanidade está resolvendo seu problema econômico" (p. 155), com o aumento da produtividade e da tecnologia. Todavia, ao contrastar o mundo futuro com o presente, Keynes constatou que o então aceito como "normal" - ou seja, os valores e virtudes enaltecidos pelo ideário liberal, internalizados nos corações e mentes voltará futuramente a ser percebido pelos homens com a mesma dimensão desabonadora vigente antes do triunfo do individualismo: "a avareza é um vício, a usura uma contravenção, o amor ao dinheiro algo detestável (...). Valorizaremos novamente os fins acima dos meios, e preferiremos o bem ao útil”' (p. 158). Como afirmam Lima e Cardoso (apud Ferrari, 2006, p. 114):

(5) Não é objetivo deste artigo a análise do método em Keynes. Dentre os autores nacionais que recentemente escreveram sobre o tema, citam-se: Rogério Andrade (2000), F. Cardim de Carvalho e Maria Aparecida G. de Souza (apud Corazza, 2003), e G. Corazza (2009), sem esquecer os trabalhos de Lawson e Pesaran (1985), O’Donell (1991), Bateman e Davis (1991), Gerrard e Hillard (1992) e Carabelli (1998). 
Pedro Cezar Dutra Fonseca

Keynes sugere que quando o problema econômico for resolvido, a sociedade encarará as relações monetárias como elas realmente são, ou seja, patologias. A partir de então, as pessoas voltar-se-ão para as coisas belas da vida, exercendo a verdadeira arte de viver.

Finalmente, no capítulo 24 da Teoria Geral, a crítica de Keynes centra-se na incapacidade da sociedade em garantir o pleno emprego e uma distribuição mais equânime da renda e da riqueza. Como assinala Carvalho (apud Ferrari, 2006, p. 45-47), Keynes "estava longe de ser um igualitarista"; todavia, entende que a proporção tomada pela desigualdade na sociedade moderna chegara a níveis intoleráveis. Novamente sua crítica ao liberalismo assenta-se em uma visão estritamente pragmática: procura expressá-la de um modo "quase técnico" (para usar a expressão de Carvalho) e evita valores explícitos. Mais que criticar os "excessos" do capitalismo e a injustiça distributiva, mostra que a concentração de renda e riqueza é disfuncional, prejudicial ao crescimento econômico e, portanto, ao próprio desempenho do capitalismo. Fica claro, mais uma vez, que sua crítica ao liberalismo não se estende ao capitalismo como sistema econômico: "Existem valiosas atividades humanas que requerem o motivo do lucro e a atmosfera da propriedade privada de riqueza para que possam dar os seus frutos" (Keynes, 1983, p. 254). Não obstante, a sociedade carece de instrumentos ou mecanismos automáticos que garantam o pleno emprego (como se mostrará na seção a seguir); há necessidade de administrar a demanda efetiva e seu principal determinante: o investimento. A necessidade de manter a taxa de juros baixa a fim de ser coberta pela eficiência marginal do capital (a taxa de retorno esperada pelo investidor) levou-o a criticar os rentistas e aplicadores do capital a juros. Keynes chegou a uma proposição paradoxal aos olhos de quem cobra das ideologias um exercício de lógica formal: como aceitar o capitalismo sem a figura do rentier, como se esta fosse uma anomalia? Assim, contrariando a teoria clássica e neoclássica, ou o mainstream econômico desde Smith, que sempre apelou para os mais variados argumentos para fundamentar economicamente a existência dos juros, defende a inexistência de qualquer razão para justificá-los, a não ser o fato de passar por uma fase transitória, na qual há escassez de capital. Os argumentos tradicionais remuneração pela espera, retribuição à abstinência, produtividade marginal do capital - não fariam o menor sentido na sociedade futura: o capital não é escasso por razões intrínsecas (como a terra, cuja oferta limitada por uma razão física permite até se entender a retribuição em forma de renda). Ironicamente lembra que, aos financistas modernos, a "taxa de juros atual não compensa nenhum verdadeiro sacrifício" (Keynes, 1983, p. 255).

A fase transitória, portanto, circunscrevia-se historicamente: não possuía caráter de inevitabilidade nem decorria de qualquer "lei natural". Poderia ser modificada por políticas, ou seja, requerer-se-ia o intervencionismo estatal com o propósito de administrar os juros, a propensão a consumir e os impostos, e, com 
isso, assegurar o crescimento dos investimentos, da demanda efetiva e do emprego. Se esta proposta pode parecer moderada em um mundo dividido entre stalinismo e nazi-fascismo, Keynes manifestava consciência tanto desse aspecto como de sua envergadura. Se, para alguns, as implicações de suas ideias poderiam afigurar-se "razoavelmente conservadoras", para outros soaria arrojado demais seu entendimento de que "uma socialização ampla dos investimentos será o único meio de assegurar uma situação aproximada de pleno emprego" (Keynes, 1983, p. 256), embora esta afirmação possa ser interpretada não como uma estatização dos investimentos, mas como a criação de um ambiente institucional favorável a ele. Seu antiliberalismo econômico, não obstante, jamais o afastou da defesa das conquistas da humanidade emergentes no bojo do Iluminismo e do liberalismo político, como os direitos civis, as liberdades políticas e a democracia representativa. Assim, o intervencionismo e a referida socialização não justificariam um "Socialismo de Estado abrangendo a maior parte da vida econômica da nação", e o individualismo "se purgado de seus defeitos e abusos, é a melhor salvaguarda da liberdade pessoal (...) da variedade da vida, que desabrocha justamente desse extenso campo das escolhas pessoais, e cuja perda é a mais sensível de todas as que acarreta o Estado homogêneo ou totalitário" (Keynes, 1983, p. 256-257). A construção de um Estado ao mesmo tempo democrático e intervencionista era o desafio num mundo polarizado entre liberalismo e estatismo autoritário: "Os regimes autoritários contemporâneos parecem resolver o problema do desemprego à custa da eficiência e da liberdade" (p. 258).

Seria esta a "utopia keynesiana", capaz de aflorar na hora em que se liberta de seu bem comportado pragmatismo? Utopia ou não, passado quase um século, a questão por ele apontada permanece na ordem do dia.

\section{A "revolução" keynesiana}

"Creio estar escrevendo um livro sobre teoria econômica que revolucionará - não imediatamente, penso, mas durante os próximos dez anos - a maneira pela qual o mundo pensa sobre os problemas econômicos", escreveu Keynes a Bernard Shaw em janeiro de 1935 (Robinson, 1978, p. 82). Cabe agora lembrar algumas dessas contribuições à teoria e à política econômica, cujo impacto permitiu a denominação, antecipada por ele, de "revolução keynesiana". Mais uma vez isso será feito tendo como foco recuperar sua crítica ao liberalismo. No caso, como esta ideologia impactou e como se expressa na teoria econômica denominada por Keynes de "clássica" - expressão empregada não apenas para designar economistas liberais do passado, como Smith, Ricardo e Say, mas mesmo contemporâneos seus, como Pigou e Marshall, que compartilhavam as teses econômicas assentadas na crença segundo a qual havia mecanismos inerentes ao 
sistema econômico responsáveis por assegurar o pleno emprego. $\mathrm{Na}$ impossibilidade de abarcar toda a vasta contribuição de Keynes, optamos por sumariar três aspectos definidores de sua contribuição crítica ao liberalismo teórico e que se refletem no modus faciendi da política econômica: (a) a não neutralidade da moeda; (b) a teoria da demanda efetiva; (c) o padrão-ouro.

Comecemos pela contribuição no campo da teoria monetária, uma vez que parte da mesma já se adiantou anteriormente ao se tratar da crítica ao rentista e aos juros. O pensamento clássico normalmente tinha como ponto de partida uma economia de trocas, assentada na divisão do trabalho e onde cada produtor individual produzia e trocava mercadorias no mercado com base em seu valor trabalho. Neste contexto, a moeda restringia-se a mero facilitador das trocas, "azeite da circulação"; não fazia sentido o entesouramento: as pessoas querem as mercadorias (no pensamento marginalista, os bens, para desfrutar sua utilidade) e não o dinheiro. Em sua origem, o ouro era apenas uma mercadoria como as outras e o fato de ter sido escolhida para desempenhar a função de intermediária das trocas em nada alterou sua natureza. Say (1983, p. 138-139, grifos meus) fora enfático: "O dinheiro é apenas a viatura do valor dos produtos", ou ainda: "O dinheiro desempenha apenas um ofício passageiro nessa dupla troca; e, terminadas as trocas, verifica-se sempre: produtos foram pagos com produtos". Não haveria entesouramento nem demanda especulativa por moeda, porque o vendedor, ao receber um pagamento, "tem pressa em desfazer-se do dinheiro que sua venda lhe propicia, para que o dinheiro tampouco fique ocioso". Este postulado clássico não teria maior importância não fosse, dentre outras consequências, (a) tornar a superprodução impossível, dedução consagrada como lei de Say: "a oferta gera a sua própria demanda". Segundo esta, para o vendedor "não é possível desfazer-se de seu dinheiro, senão procurando um produto qualquer. Vê-se, portanto, que só o fato da criação de um produto abre, a partir desse mesmo instante, um mercado para os outros produtos" (grifos meus); e (b) servir de sustentáculo à teoria quantitativa da moeda, de onde se deduzia a inflação como um fenômeno exclusivamente monetário e resultado da oferta monetária além da taxa de crescimento do produto. Para tanto, admitia-se a velocidade de circulação da moeda e a quantidade produzida como constantes a curto prazo.

A contrariedade de Keynes a essa simplificação começou muito antes da crise de 1929 e apareceu de uma forma mais acabada já em seu A treatise on money, de 1930, onde já aparece a formulação de sua teoria de escolha de ativos, com a clara distinção entre circulação financeira do capital e circulação industrial do capital. Na Teoria Geral, ocupou lugar de destaque, pelo que já se alertava o leitor no prefácio:

O presente livro, por outro lado, evoluiu (...) se descubra que a moeda entra no esquema econômico de uma maneira essencial e peculiar (...). Uma economia 
monetária, iremos ver, é essencialmente uma economia em que as mudanças de pontos de vista sobre o futuro são capazes de influenciar o volume de emprego e não meramente a inflação (Keynes, 1983, p. 4, grifos meus).

Embora na Teoria Geral Keynes tenha suposto a exogeneidade da oferta de moeda, ou seja, a capacidade de fixação de sua quantidade pelas autoridades monetárias, outras obras suas permitem a leitura da oferta de moeda endógena, como no já citado A treatise on money (Keynes, 1976), onde incorpora o papel do sistema financeiro na análise e parte do comportamento da demanda de moeda depende do finance motive (com a consequente interação entre as decisões das autoridades monetárias e dos agentes econômicos).

Mas o capítulo 17 da Teoria Geral é o mais famoso e recuperado pelo pensamento pós-keynesiano. Intitulado "As propriedades essenciais do juro e do dinheiro", nele Keynes se propõe a mostrar como esse toma na sociedade capitalista uma dimensão muito maior do que teria sido sua função originária: "a característica da moeda, enfim, é ter um rendimento nulo, um custo de manutenção insignificante, porém um prêmio de liquidez substancial" (Keynes, 1983, p. 159). O dinheiro não se confunde com as outras mercadorias porque sua elasticidade de produção é zero, visto ser produzido pela autoridade monetária com custos desprezíveis; sua elasticidade de substituição também é praticamente zero, ou seja, não possui substitutos à altura; e, finalmente, possui alta elasticidade de procura como reserva de valor, pois, mesmo diante de oferta maior, sua remuneração - a taxa de juros - não cai na mesma proporção, uma vez que ainda é forma preferível para manter a riqueza com relação a outras opções. Este capítulo dá guarida à interpretação segundo a qual as autoridades monetárias têm seu poder limitado na fixação da oferta monetária por condições endógenas, ou inerentes ao sistema econômico, como a incerteza e o entesouramento. Os agentes econômicos reagem às decisões governamentais e têm seu comportamento marcado pela imprevisibilidade: daí a oferta de moeda tornar-se "endógena".

Isto posto, ao contrário do que argumentavam Say e os clássicos, as pessoas poderiam querer moeda não apenas para suas transações, mas porque aquela possui propriedades intrínsecas, é passível de ser entesourada e representa a forma mais líquida de valor. Esta é a parte da obra de Keynes mais próxima a Marx: o dinheiro traz consigo a possibilidade de crises. Ele não é neutro, o que se expressa na preferência pela liquidez, marcada por decisões descentralizadas e pela incerteza sobre o futuro com que se deparam os agentes econômicos, os quais nele buscam "refúgio" ou proteção pois é o único ativo capaz de permitir a flexibilidade de poder ser trocado por todos os outros.

Na expressão de Mollo e Amado (apud Ferrari, 2006, p. 156), em Keynes há uma "incerteza radical, não probabilizável, que conduz à preferência pela liquidez". Esta joga contra o nível de produção e emprego, e daí sua aversão ao 
usurário: este personifica o ganho que prescinde do investimento produtivo, e o custo de forçá-lo a abrir mão da liquidez materializa-se em taxas de juros cada vez mais altas. A demanda especulativa de moeda, portanto, é a novidade teórica que ajudou a explicar o não-investimento e, de certa forma, sintetiza o ambiente de incerteza dos agentes com relação ao futuro. Em adição, traz como corolário limitações à teoria quantitativa da moeda e, portanto, à relação entre oferta de moeda e inflação. A velocidade de circulação da moeda - que pode ser lida como o inverso da propensão a entesourar - não pode ser mais considerada como constante a curto prazo, pois varia com o clima de incerteza e instabilidades inerentes às economias de mercado. A moeda deixa de ser exógena, ou seja, a Autoridade Monetária perde poder de controle sobre sua oferta.

Assim, a endogeneidade da moeda e sua não neutralidade refletir-se-ão na formulação da política econômica. O nível de preços deixa de ser proporcional à oferta monetária, posto que pode resultar de alterações da velocidade de circulação da moeda e, por outro lado, os níveis de renda real e de emprego são afetados, de forma duradoura, pelo lado monetário da economia. Por conseguinte, seja devido à neutralidade ou pela exogeneidade da moeda, os postulados clássicos traziam consigo a legitimação da passividade das autoridades monetárias. Nesse momento, fica claro que as objeções de Keynes ao laissez-faire, além de sua revolução teórica propriamente dita, recaem em cheio sobre a prática da política econômica. Admitir a velocidade como constante implicava não atuar sobre ela, ou seja, desse pressuposto teórico resultava uma postura de não intervenção do governo. Este deveria restringir-se à austeridade monetária e fiscal para combater a inflação, o que acabava por incidir negativamente sobre os níveis de atividade econômica e do emprego - sem surtir o mesmo efeito no combate à inflação. Rechaçar o mito arraigado de que oferta de moeda induz simplesmente a mais inflação foi das atitudes mais corajosas de Keynes contra a ortodoxia de seu tempo.

Seu raciocínio, todavia, é mais complexo do que mostrar a relação entre preferência pela liquidez e incerteza, bem como seu reflexo na relação inversa entre taxa de juros e nível de investimentos. Ele interliga os lados real e monetário da economia, separados na teoria clássica, e pondera haver momentos nos quais as taxa de juros, mesmo baixas, não são capazes de induzir o investimento. As decorrências e a relevância desta proposição podem ser mais bem elucidadas ao se abordar o segundo aspecto anteriormente proposto: a demanda efetiva.

Como se viu, a neutralidade da moeda da economia clássica e o entendimento de que se restringia a um facilitador das trocas vincula-se, como contrapartida (e no lado real da economia), à "lei de Say". Essa sintetiza o entendimento de que tudo o que é produzido deve ser demandado, desde que haja flexibilidade de preços. Economia de mercado com desemprego e superprodução, em decorrência, constitui uma contradição em termos, uma impossibilidade teórica 
e fática. Mas como as crises existiam a despeito das demonstrações teóricas em contrário, os clássicos passaram a tratá-las, em geral, como excepcionalidade, ou temporárias, ou, ainda, como resultantes da própria interferência do governo: este, ao tentar ajudar, apenas retardava o equilíbrio inerente às forças de mercado. Mais uma vez, a melhor política era não ter política alguma. Keynes inverteu a relação de causalidade - no que talvez seja seu insight mais profícuo: é o fluxo de gastos que gera a renda, de modo que é a demanda a responsável pelo aumento da produção. Esta inversão ia ao encontro, mais uma vez, da razão prática: as crises frequentes de superprodução e os ciclos econômicos, já visíveis e duradouros no século XIX, careciam de uma explicação e chocavam-se com os modelos dos economistas do mainstream. E, em adição, feria um ponto central do individualismo, sacramentado pela ética protestante: a apologia à poupança. Joan Robinson (1980, p. 203) literariamente expressa o paradoxo e o contraste entre a teoria e mundo extramuros da academia:

Eu era estudante à época em que a economia vulgar estava em um estado especialmente vulgar. Havia na Grã-Bretanha pelo menos um milhão de trabalhadores desempregados e meu próprio orientador de estudos me ensinando que o desemprego é logicamente impossível diante da lei de Say.

Se a demanda era a variável por excelência, cabia desagregá-la. A forma encontrada, voltada a desvendar os determinantes dos gastos, recaiu sobre o agente econômico ou segmento social responsável por cada parcela sua. Com isso, deslocou-se a unidade de análise dos indivíduos para os agregados macroeconômicos. Assim, a demanda agregada compõe-se de quatro variáveis: o consumo das famílias (C), o investimento privado (I), os gastos governamentais (G) e a demanda externa, exportações menos importações $(\mathrm{X}-\mathrm{M})$. O estudo dos determinantes de cada uma destas variáveis tornou-se programa obrigatório nos cursos introdutórios de macroeconomia no mundo inteiro, e sua mensuração tarefa inescapável dos governos do pós-Segunda Guerra: a Contabilidade Social integrava-se ao saber básico dos economistas. E, mais uma vez, a crítica ao liberalismo emerge com a tentativa de evitar juízos de valor explícitos, mas com a demonstração de sua irrealidade ou inaplicabilidade ao mundo real. Assim, os argumentos de Keynes são:

a) O consumo (C) não é a variável responsável por variações da renda (ou do produto, identidade trazida pela Contabilidade Social), pois é função da própria renda. O "subsconsumismo", como o de Malthus (e, quiçá, Rosa Luxemburg), invertera esta função ao atribuir ao baixo consumo a responsabilidade maior pelas crises. A "função consumo" de Keynes postula que, no curto prazo - e, portanto, para uma dada distribuição de renda -, o consumo é a variável dependente, e responde passivamente aos crescimentos da renda. A decisão de quanto consumir é posterior à obtenção da renda; por outra ótica, primeiro há de haver produção 
para depois haver consumo. Esta proposição inverte a percepção usual, mesmo para quem olha a economia pelo lado da demanda. Sua construção teórica, todavia, é mais complexa, pois permite a interpretação de que o consumo é determinado e também é determinante do nível de renda, uma vez que o multiplicador depende da propensão marginal a consumir. Na Grande Depressão, havia economistas que aconselhavam, diante da crise, que o governo deveria incitar as pessoas a gastar. Keynes entendia que esta medida era insuficiente (embora melhor do que não fazer nada), bem intencionada, porém inócua: como incitar as pessoas ao gasto, se estavam desempregadas? Com queda no nível de renda, como reverter a crise a partir do consumo? No máximo, este poderia apresentar um crescimento temporário, como uma "bolha": as empresas poderiam se desfazer de estoques indesejados, mas dificilmente começariam a contratar novos trabalhadores para diminuir o grau de capacidade ociosa já existente e, muito menos, partir para novos investimentos. Como retomar estes últimos era, por conseguinte, o "x" da questão;

b) O investimento (I) é a variável determinante da demanda agregada. É o principal responsável pelas flutuações econômicas: ao contrário do consumo, é determinante e não determinado; não é apenas parte da renda, como à primeira vista sugere a composição da demanda agregada, mas sua origem. A importância das flutuações do investimento no nível de produção é ainda majorada com a noção de multiplicador: um impacto no investimento, positivo ou negativo, causa uma variação na produção igual ao montante do investimento vezes um múltiplo. Todavia, se o investimento possui toda esta relevância, a outra proposição central de Keynes diz respeito a sua instabilidade e imprevisibilidade. O investimento é um ato privado que depende de expectativa de retorno; ao investir, ninguém tem certeza se e quanto vai ganhar. Envolve, mais que risco, um cálculo probabilístico, mas também a incerteza, a qual não se pode associar a uma probabilidade. Depende de fatores longe do alcance do empresário e de sua possibilidade de previsão: inovações tecnológicas, decisões dos concorrentes, variáveis políticas, comportamentais e institucionais, mudanças na legislação, reação dos consumidores, comércio internacional, preço de venda do bem produzido ao longo do tempo, clima, ciclos dos negócios, etc. Não há como calcular "tecnicamente" tal taxa ou "eficiência marginal" sem que se estabeleçam determinados parâmetros, todos dependentes de expectativas, as quais podem ou não se realizar. A taxa de juros é apenas uma variável a mais a influir na decisão de investir; mesmo sua queda não garante expansão da demanda agregada em um ambiente de incerteza. Ao contrário de conduzir ao equilíbrio e à instabilidade, o liberalismo (ou seja, uma economia de dois setores, apenas com famílias e empresas) traz consigo as crises, o desemprego, as flutuações abruptas e os ciclos econômicos. Além do mais, em uma economia liberal - ou seja, na ausência de um setor público que desempenhe, com seus gastos, papel anticíclico - a instabilidade do 
investimento privado, associada a sua relevância na determinação dos níveis de renda e emprego, confere grande influência política aos empresários: qualquer fator perturbador das expectativas afeta negativamente os investimentos e, por conseguinte, o nível de atividade econômica, acarretando queda na arrecadação de impostos e no emprego de milhares de trabalhadores. Coube a Kalecki (1977), de forma mais incisiva que Keynes, explorar esse fato em artigo clássico intitulado "Os Aspectos Políticos do Pleno Emprego", de 1943. ${ }^{6}$

Diante deste contexto, só restariam duas alternativas para contra-arrestar os ciclos econômicos: o governo e o setor externo. Invertamos a ordem e abordemos primeiramente este último;

c) O setor externo $(\mathrm{X}-\mathrm{M})$ fora a saída usual encontrada por países europeus hegemônicos, como a Inglaterra, ao longo século XIX. A expansão da produção, viabilizada pela conquista dos mercados externos, despertou, por sua força como poder de explicação para as crises cíclicas, o aparecimento de diversas "teorias do imperialismo", as quais, sob diversos argumentos, responsabilizavam o colonialismo como a saída encontrada pelos países industrializados para contraarrestá-las. Keynes, todavia, não só desprezava estas explicações como se mostrava cético quanto a essa possibilidade no século XX. Nesse contexto, devese mencionar sua aversão ao gold-exchange standard, regra institucional simbólica da libra esterlina como dominante, já em seus primeiros escritos, como Indian Currency and Finance, de 1913. Segundo Ferrari (2006, p. 17), três motivos teriam sido levados em consideração por ele: “(i) tornar mais elástica a liquidez internacional, visto que essa é imprescindível para expandir os volumes de comércio e de produção mundiais; (ii) fazer com que a política monetária fosse mais ativa e, por conseguinte, eficiente, seja para estabilizar os níveis de preços, seja para, de forma contracíclica, dinamizar os níveis de renda e emprego; e (iii) seu ceticismo acerca do mecanismo de ajustamento automático do balanço de pagamentos sob as regras do regime de padrão-ouro". Este se consubstanciava como a regra ortodoxa mais marcante do comércio internacional, trazendo consigo como corolário o ajuste automático dos balanços de pagamentos, se respeitado o princípio do laissez-faire - pelo que a crença materializava-se também como uma regra de política econômica. Na década de 1930, diante da crise internacional, a proposta de contar com o setor externo afigurava-se como quimera. No capítulo 5 de A Tract on Monetary Reform, chegou a afirmar que havia um trade off entre as políticas monetária e cambial; entre ambas, preferia a estabilidade dos preços à do

(6) A seguinte passagem de Kalecki sintetiza seu argumento: "Em um sistema de laissez-faire o nível de emprego depende, em grande parte, do assim chamado estado de confiança. Se este se deteriora, o investimento privado declina, do que resulta uma queda do produto e do emprego (tanto diretamente como através do efeito secundário que a queda das rendas exerce sobre o consumo e o investimento). Isso dá aos capitalistas um poderoso controle indireto sobre a política governamental: tudo que possa abalar o estado de confiança deve ser cuidadosamente evitado, porque causaria uma crise econômica" (Kalecki, 1977, p. 55). 
câmbio, ou seja, admitia o abandono do padrão-ouro e da rigidez a qual lhe era inerente. Por isso, "the gold standard is already a barbarous relic" (Keynes, 1971, p. 138). Apesar das referências ao comércio exterior e de um capítulo sobre mercantilismo na Teoria Geral, essa pode ser interpretada como um modelo de economia fechada. ${ }^{7}$ Como lembra Skidelsky (2009): “A mensagem de Keynes era, efetivamente, esta: cuide-se bem da economia interna e a internacional cuidará de si mesma" (Cf. Keynes, 1977, p. 70). A solução proposta por Keynes revela não apenas pragmatismo, já que na crise generalizada um país não poderia resolver seu problema exportando para outro, mas algo mais profundo: a convicção de que a hegemonia da Grã-Bretanha e da libra esterlina havia sido enterrada com a Era Vitoriana. Assim, só restava como alternativa:

d) Os gastos governamentais (G). Esta conclusão de Keynes, marca mais difundida de sua contribuição, resultava de uma necessidade prática e advinha da exclusão das outras variáveis. A ampliação da agenda do governo não se devia a uma opção política ou doutrinária, muito menos gosto pelo intervencionismo ou pelo socialismo: consistia na única alternativa possível. Os conservadores teriam que engolir este remédio amargo.

\section{Por uma nova alternativa}

Apesar de o pensamento de Keynes, ao tratar do liberalismo, apresentar pontos surpreendentes e até "incoerentes" aos olhos da atualidade, há uma constante em todos seus escritos tanto econômicos como aqueles nos quais aborda temas filosóficos e políticos: o repúdio às grandes correntes políticas que dividiram os homens e as nações de seu tempo, tais como o nazi-fascismo, o socialismo e o liberalismo. A rebeldia contra as três alternativas marca sua trajetória; as ênfases ao criticar uma e outra, ao longo de seus escritos, emprestalhe ora um tom conservador ora um caráter extremamente crítico e insatisfeito com o status quo. Dois papers dos Essays in persuasion ajudam a esclarecer melhor seu posicionamento: "Sou um Liberal?", de 1925, e, do ano seguinte, "Liberalismo e trabalhismo". 8

Menções críticas ao nazi-fascismo são recorrentes em sua obra. Todavia, pouco avançava nos argumentos: parecia julgar suficiente a condenação moral a estes regimes por sua violência e estupidez. O desafio de enfrentar os males do laissez-faire sem sacrificar as liberdades individuais sempre o acompanhou de perto. E daí sua indisposição também com relação ao socialismo e a Marx, que em

(7) Para aprofundar sobre a visão de Keynes sobre o padrão-ouro, outra obra importante, além de $A$ tract on monetary reform, é: Activities 1929-1931 - Rethinking employment and unemployment policies (Keynes, 1981).

(8) Ver Keynes (1972); todas as citações a seguir, a não ser com menção em contrário, foram daí extraídas, com tradução - na medida do possível - literal; os grifos são originais.

Economia e Sociedade, Campinas, v. 19, n. 3 (40), p. 425-447, dez. 2010. 
vários momentos avalia como indissociável do stalinismo. Sua opção pelo Partido Liberal pode parecer uma contradição mais pelo nome do partido do que propriamente por sua ideologia, o que se esclarece quando o autor expõe suas razões e, principalmente, se tivermos presente a vasta gama de sentidos que o termo "liberal" pode assumir, por exemplo, ao abarcar desde o intransigente defensor do livre mercado até um tom de "quase" socialismo ou radicalismo na defesa dos direitos sociais, ambientais ou das minorias, como em alguns países atualmente. Keynes, todavia, dedica mais tempo em mostrar o porquê de não optar pelos outros dois partidos - o Trabalhista e o Conservador - do que a justificar sua opção. Lança mão de recurso discursivo semelhante ao antes mencionado com relação à demanda efetiva e aos gastos governamentais: a opção preferida resulta da exclusão das demais alternativas.

Com relação ao Partido Trabalhista, torna-se impossível não mencionar uma passagem citadíssima de "Sou um liberal?":

Para começar, é um partido de classe, e a classe que não é a minha. Se for perseguir interesses parciais, perseguirei os meus próprios. Quando chegar a luta de classes como tal, meu patriotismo local e pessoal, como os de qualquer outro, exceto alguns entusiastas desagradáveis, estará vinculado a meu próprio ambiente. Posso me deixar influenciar pelo que me parece justiça e bom senso, mas a luta de classes me encontrará do lado da burguesia esclarecida (Keynes, 1972, p. 297).

O entendimento de que o Partido Trabalhista era impregnado por pessoas propensas ao radicalismo e a debates ideológicos infindáveis chocava-se com seu senso prático. Recorre a vários adjetivos ao se referir a seus membros: como "partido da catástrofe", abrigava "jacobinos, comunistas, bolcheviques, ou como se queira chamar-lhes". Reconhece que nem todos os membros do partido poderiam enquadrar-se como tal, mas sugere sua indisposição em conviver com aqueles que desdenhavam das instituições democráticas britânicas, mesmo reconhecendo que os radicais eram minoritários dentro da própria agremiação. Ainda em “Sou um Liberal?", menciona que o Partido Trabalhista compunha-se de três tipos: (a) os sindicalistas, "antes oprimidos e agora tiranos", com pretensões egoístas e setoriais, a quem se lhes devia opor energicamente; (b) os comunistas, defensores de métodos violentos, dispostos a produzir o mal para alcançar o bem e a tramar conspirações; e (c) os socialistas, à primeira vista mais afáveis, ao crerem que "os fundamentos da sociedade moderna são maus, mas poderiam ser bons". Todavia, na prática, o caminho do socialismo de Estado lhe parecia insuficiente: "Estas doutrinas já não inspiram nada". O caminho buscado deveria ser outro, diferente do defendido por aqueles que manifestam "ódio e inveja" aos que possuem riqueza e poder, os quais "dificilmente se associam com os ideais para construir uma verdadeira república social". Como bom construtor de frases, sintetizou no mesmo artigo: "Para que um líder sindical tenha êxito, é necessário 
ser um pouco selvagem, ou pelo menos que aparente isso. Não basta que ame seus semelhantes; deve odiá-los também" (Keynes, 1972, p. 300-301).

Já com relação ao Partido Conservador, o teor da crítica muda, mas não seu vigor. Este é visto como o locus dos "intransigentes da direita", com valores e ideais do passado, associado às glórias do império, à aristocracia, ao orgulho de descendência, aos proprietários de terra e aos valores tradicionais, como direitos de propriedade, preconceitos religiosos e morais, discriminação sexual e aos direitos femininos. Contraditoriamente, os conservadores associam estes valores a rigor medievais e mais próprios ao sistema feudal - à ética do individualismo exacerbado, atraindo os líderes capitalistas e a City londrina, os quais não conseguiam entender que o mundo mudara e se faziam necessárias novas medidas, inclusive "para salvaguardar o capitalismo do que eles chamam de bolchevismo". Tal como os líderes trabalhistas, os conservadores também possuíam em seu círculo intransigentes, defensores da herança para justificar a desigualdade, argumento "débil e estúpido", capaz de justificar o ganho sem trabalho, sem risco, sem esforço: "Nada produzirá a decadência de uma instituição social com mais certeza que sua adesão ao princípio hereditário". Assim, a eles também não poupa adjetivos: os adeptos do liberalismo "do laissez-faire e do livre jogo das forças econômicas", entre os quais os da City, são "truculentos", "cegos" e "religiosos" (Keynes, 1972, p. 307).

Destarte, o Partido Liberal deveria encampar projeto alternativo aos extremos. Assumir a liberdade civil e religiosa, o voto universal, a questão irlandesa, o autogoverno dos domínios ingleses no mundo, o imposto progressivo, a seguridade para saúde, educação, habitação - enfim, abandonar os valores do individualismo liberal e buscar justiça social dentro de uma sociedade aberta. Conforme suas palavras, em "Liberalismo e trabalhismo": "O problema político da humanidade consiste em combinar três coisas: eficiência econômica, justiça social e liberdade individual" (Keynes, 1972, p. 309). Um partido - o Conservador estaria mais propenso a defender a primeira e a última, com sacrifício da segunda, enquanto esta constituía o maior patrimônio do Partido Trabalhista. Dever-se-ia buscar uma nova alternativa capaz de amalgamar os três objetivos, de modo que também a política econômica pudesse, ao mesmo tempo, buscar estabilidade (normalmente negligenciada pelos líderes sindicais) com justiça social. Keynes manifesta sua convicção de que sem os trabalhadores e suas lideranças dificilmente se teria respaldo para implementar grandes mudanças. Reitera inúmeras vezes a necessidade de buscar o novo. A polaridade capitalismo versus socialismo afigura-se-lhe pobre e maniqueísta; fazia-se mister construir uma nova alternativa, como propõe adiante, no mesmo artigo: "O Partido Liberal não deve ser menos progressista que o trabalhista, nem menos aberto às novas ideias, nem 
atrasado na construção do novo mundo" (Keynes, 1972, p. 309). E este era também o desafio aos intelectuais:

A metade da sabedoria de caderno de caligrafia de nossos estadistas se baseia em supostos que foram verdadeiros, ou parcialmente verdadeiros, em sua época, mas que agora são cada vez menos verdadeiros, à medida que passam os dias. Temos que inventar uma nova sabedoria para uma nova época. E entretanto devemos, se havemos de fazer algo bom, parecer heterodoxos, incômodos, perigosos e desobedientes com os que nos têm forjado (Keynes, 1972, p. 305).

\section{Conclusão}

A leitura da obra de Keynes tendo como foco sua visão sobre o liberalismo econômico evidencia pelo menos duas regularidades, recorrentes em praticamente todos os textos analisados: (a) a descrença no laissez-faire, motivação maior a incitá-lo como intelectual e homem de seu tempo; e (b) a ênfase no argumento pragmático, com base na experiência e no impacto de suas consequências, como sustentáculo para sua reflexão teórica e defesa de suas políticas de intervenção na realidade.

Com relação à primeira e sua aversão à ortodoxia teórica dominante desde Smith e Ricardo, resta indubitável que o diálogo preferencial é com seus defensores: é contra a ortodoxia liberal que se dirige em quase a totalidade de suas obras. A alternativa pretendida é para se contrapor ao liberalismo hegemônico há mais de um século - o qual o irrita a ponto de dizer que "Ricardo conquistou a Inglaterra de maneira tão completa como a Santa Inquisição conquistara a Espanha" (Keynes, 1983, p. 34) - frase cuja denotação remete à predominância do sentido emocional sobre o racional da conquista. As outras ideologias dominantes de seu tempo - o nazi-fascismo e o comunismo soviético - também mereceram críticas, mas estas são mais raras e, muitas vezes, descartadas a limine como alternativas. De forma explícita ou não, adotava o pressuposto de buscar uma sociedade com menos disparidades sociais e mais humana, mas sem abrir mão da liberdade, dos direitos civis e políticos, da propriedade e do reconhecimento pelo esforço e pelo mérito. Segundo Joan Robinson, descrevia-se como um "conservador moderado" e seu ânimo frequentemente "pendia da esquerda para a direita. Se o capitalismo lhe era (em certos aspectos) repugnante, o stalinismo the causava impressão ainda pior. Nos últimos anos de sua vida é certo que a direita predominou" (Keynes, 1977, p. 106-107). O leitor de "Sou um Liberal?", curioso em obter a resposta, sai frustrado: depois de toda a argumentação desenvolvida, a última frase do artigo consiste na repetição de seu próprio título. Mas é nele que Keynes expõe um programa de novas ideias ao Partido Liberal, ao qual então sugere inventar um "novo liberalismo". Já em "Liberalismo e Trabalhismo" mostra simpatia pela tipologia de "liberal progressista". 
Diante desse quadro, a opção pelo Partido Liberal parecia a menos comprometedora. Uma saída "pelo centro", tudo sugere, comovia-o por evitar os intransigentes, os violentos e os guiados mais por interesses parciais - individuais ou de classe -, os quais recorriam a ideias mirabolantes ou ultrapassadas, ambas, de qualquer forma, sem o menor senso prático. Há quem associe esta visão à Social-Democracia do pós-Segunda Guerra. Todavia, essa começou a ser gestada bem antes de Keynes, pois remonta ao final do século XIX, com gênese no próprio movimento dos trabalhadores, com a divisão entre comunistas e socialdemocratas na II Internacional Socialista. Seu ideário - a preferência por participar do jogo eleitoral, por reformas dentro da legislação e pela socialização gradual dos setores básicos da economia - certamente após a II Guerra encontrou nas teses de Keynes um importante respaldo, principalmente após a chegada desses partidos ao poder em vários países europeus. O movimento socialista desde seu nascedouro concentrara seus esforços intelectuais e sua energia na defesa da construção de uma nova sociedade; tarefa diferente era administrar a sociedade capitalista com outros valores e objetivos, diferentes da ortodoxia liberal. As teses de Keynes caíram como uma luva para os defensores do intervencionismo econômico, da opção pelo pleno emprego e pelos impostos progressivos do Welfare-State. Como enquadrar tais ideias no espectro político? A valer a reflexão de Bobbio (1995, p. 91-100), para quem a díade "direita e esquerda" não está ultrapassada, estes não denotam conceitos substantivos ou ontológicos, pois não designam conteúdos fixados de uma vez para sempre, mas denotam posições relativas no "espaço político" no tempo histórico. Todavia, a direita normalmente considera a desigualdade como natural e a esquerda como decorrente principalmente de motivos sociais (o que não se confunde com o igualitarismo, cuja utopia consiste em propor "igualdade de todos em tudo"). Assim sendo, para a esquerda a desigualdade poderia/deveria ser objeto de políticas públicas e, em boa medida, eliminável (com exceção daquelas, por exemplo, de responsabilidade do próprio indivíduo). Esse parece ser o caso de Keynes, sem esquecer a relatividade posicional antes mencionada (cf. Keynes, 1977, p. 91-100).

Na América Latina, algumas teses de Keynes assumiram um ar ainda mais crítico e transformador ao se somarem às ideias desenvolvimentistas que vinham sendo gestadas desde o final do século XIX. Essas remontam, embrionariamente, ao positivismo, com fortes adeptos em segmentos da elite civil e militar de vários países do subcontinente, e apregoava caber ao Estado auxiliar na linha evolutiva da sociedade em direção ao progresso (Fonseca, 2000, 2004). Vários economistas da tradição cepalina, a partir da década de 1950, como Raul Prebisch e Celso Furtado, admitem influência de Keynes em suas obras. Todavia, parece-nos exagero afirmar, como Simonsen $(1969$, p. 83), que "os estruturalistas avançaram demais na admiração keynesiana, tentando transpor o modelo de Keynes para um caso particular que ele nada tem de aplicável”. Contrariamente, os economistas 
latino-americanos tinham por objeto o subdesenvolvimento - tema com o qual Keynes não se ocupara. Todavia, não há evidências de que se tratava de mera transposição, pois desde os primeiros manifestos da Cepal evidenciou-se a consciência da particularidade das economias latino-americanas; uma das marcas do pensamento cepalino reside justamente em evitar "copiar' ou "adaptar" teorias, numa crítica à universalidade das "leis econômicas". Ademais, seus trabalhos enfocam modelos de longo prazo, cuja ênfase residia no papel da tecnologia e na necessidade de aumentar o estoque de capital per capita, frente sua escassez relativa diante de uma oferta ilimitada de mão-de-obra, o que ocasionava um desemprego estrutural - preocupação bastante diversa do desemprego involuntário ou cíclico da obra de Keynes.

Finalmente, com relação aos apelos ao senso prático e à razão pragmática, assim se manifestou na "Teoria Geral", dentre inúmeras passagens: "Nossa crítica à teoria econômica clássica geralmente aceita consistiu menos em revelar os defeitos lógicos de sua análise do que em assinalar o fato de que as suas hipóteses tácitas nunca ou quase nunca são satisfeitas, com a consequência de que ela se mostra incapaz de resolver os problemas econômicos do mundo real" (Keynes, 1983: p. 256). Em outro trabalho, menciona que as crenças no "individualismo fora de moda" podem até não terem sido errôneas no contexto em que nasceram, posto que "contribuíram em grande medida para o êxito do século XIX"; todavia, "deixaram de ser aplicáveis às condições modernas" (Keynes, 1972). Vários analistas da obra de Keynes reiteram esta interpretação, de modo que pode-se considerar bastante provável a hipótese segundo a qual não se tratava apenas de um enfoque trazido à liça para expressar seu antiliberalismo em matéria de economia, mas uma postura que permeia sua obra como um todo. Neste sentido, Skidelsky chega a mencionar que o keynesianismo nasceu "não na busca de uma explicação teórica do desemprego, mas, sim, da convicção do próprio Keynes de que 'as doutrinas do laissez-faire (...) não são mais aplicáveis às modernas condições” (Keynes, 1977, p. 63). J. Hicks lembra que ele se abstinha de buscar objetivos muitos distantes: "meu interesse reside na obtenção de resultados diretos - nada mais" (Moddridge apud Keynes, 1977, p. 45). Joan Robinson (1978, p. 30, 34), na mesma direção, assevera: "Hitler já havia descoberto como curar o desemprego antes que Keynes acabasse de explicar por que ele ocorria”, e, talvez por isso, ele "escrevia e argumentava contra a ortodoxia predominante. Tinha que argumentar sempre que era possível fazer alguma coisa". Coube a Harry Johnson mostrar que o mito das velhas ideias com que se defrontava entrelaçava-se historicamente com outro, o qual havia interesses a preservar: "o mito cada vez mais tênue de uma Inglaterra rica e poderosa” (Keynes, 1977, p. 85).

Como todo mito, esse tinha lá sua razão de ser e acabava por servir a inúmeros propósitos. Em várias passagens, Keynes perguntou-se como aforismos 
tão primários puderam lograr tão grande aceitação: "Recorre-se à analogia entre o poder da escola clássica e o de certas religiões, pois é a maior prova da força de uma ideia esconjurar a evidência do que introduzir nas ideias comuns do homem o recôndito e o remoto" (Keynes, 1983, p. 239). Os mitos normalmente conjugam elementos extrarracionais e intuitivos com racionais, e fazem uso da linguagem simbólica e da simbolização para expressar conhecimentos, vontades e percepções. Nesse sentido, a observação de Keynes capta a simbiose contraditória entre a utopia do laissez-faire e a teoria econômica "científica", ou “experimentação mental”, que o sustenta. Segundo Gurvitch (apud Bobbio, 2004, p. 758), o mito não raro transforma-se em Weltanschauung e, sucessivamente, em ideologia: a utopia que lhe é inerente transforma a história para julgá-la em nome de arquétipos míticos; mas "fá-lo construindo modelos racionais de comportamento". Essa última observação, pela similitude, parece que foi escrita pensando na forma com que Keynes criticou os modelos econômicos dos economistas clássicos. O mito de um mundo autorregulado, com forças espontâneas de mercado tendendo inexoravelmente a um equilíbrio maximizador, sempre lhe causou espécie. Feria seu senso prático a crença inabalável na racionalidade dos homens assumida como axioma e em expectativas que sempre se realizam, sem risco nem incerteza, como se não existisse história nem conflitos, crises, incertezas, erros e decepções. Keynes contribuiu para abalar as velhas crenças, mas, a valer seu próprio método, a experiência também demonstra que infelizmente elas resistem e têm a capacidade de renascer das cinzas.

\section{Referências bibliográficas}

ANDRADE, R. P. de. A agenda do keynesianismo filosófico: origens e perspectivas. Revista de Economia Política, v. 20, n. 2, abr./jun. 2000.

BATEMAN, B. W.; DAVIS, J. B. (Ed.). Keynes and philosophy - Essays on the origin of Keynes's thought. Aldershot: Edward Elgar, 1991.

BACKHOUSE, Roger E.; BATEMAN, Bradley W. Keynes and capitalism. History of Political Economy, n. 41, p. 645 - 671, Winter 2009.

BELlUZZO, L. G. O retorno do mestre. Folha de São Paulo, Caderno Dinheiro 18 out. 2009.

BOBBIO, N. Direita e esquerda; razões e significados de uma distinção política. São Paulo: Unesp, 1995. et al. Dicionário de política. Brasília: UNB/São Paulo: Imprensa Oficial, 2004.

CARABELLI, A. M. On Keynes's method. London: Macmillan, 1988.

CATEPHORES, G. Keynes as a burgeois marxist. International Papers in Political Economy, University of East London, v. 7, n. 1, 2000.

CORAZZA, G. (Org.). Métodos da ciência econômica. Porto Alegre: UFRGS, 2003. 
FERRARI FILHO, F. (Org.). Teoria Geral, setenta anos depois. Porto Alegre: UFRGS, 2006.

FONSECA, P. C. D. As origens e as vertentes formadoras do pensamento cepalino. Revista Brasileira de Economia, Rio de Janeiro, v. 54, n. 3, jul./set. 2000.

- Gênese e precursores do desenvolvimentismo no Brasil. Pesquisa \& Debate, São Paulo, PUCSP, v. 15, n. 2(26), p. 225-256, jul./dez. 2004.

GERRARD, B.; HILLARD, J. The philosophy and economics of J. M. Keynes. Aldershot: Edward Elgar, 1992.

JAMES, W. Pragmatismo e outros textos. São Paulo: Abril Cultural, 1979.

KALECKI, M. Crescimento e ciclo das economias capitalistas. São Paulo: Hucitec, 1977.

KEYNES, J. M. A tract on monetary reform. London: Macmillan, 1971. (The Collected Writings of John Maynard Keynes, v. IV).

. Essays in persuasion. London: Macmillan, 1972.

A treatise on money. New York: AMS Press, 1976.

. Keynes: economia. São Paulo: Ática, 1978.

Activities 1929-1931 - Rethinking employment and unemployment policies. 1981. (The Collected Writings of John Maynard Keynes, v. XX).

1983.

. A teoria geral do emprego, do juro e do dinheiro. São Paulo: Abril Cultural, 1977.

(Org.). Ensaios sobre John Maynard Keynes. Rio de Janeiro: Paz e Terra,

LAWSON, T.; PESARAN, H. (Ed.). Keynes' economics: methodological issues. London: Croom Helm, 1985.

NAPOLEONI, C. Smith, Ricardo, Marx; considerações sobre a história do pensamento econômico. Rio de Janeiro: Graal, 1978.

O’DONELL, R. (Ed.). Keynes as philosopher-economist. London: Macmillan, 1991.

POLANYI, Karl. A grande transformação: as origens de nossa época. Rio de Janeiro: Elsevier, 2000.

ROBINSON, J. Contributions to modern economics. Oxford: Basil Blackwell Publisher, 1978.

Publisher, 1980.

Further contributions to modern economics. Oxford: Basil Blackwell

SIMONSEN, M. H. O pensamento estruturalista. Brasil 2001. Rio de Janeiro: Apec, 1969.

SKIDELSKY, R. Keynes: the return of the master. New York: Public Affairs, 2009. 